\title{
Effect of Process Parameters of CNT Containing Friction Powder on Flexural Properties and Friction Performance of Organic Brake Friction Materials
}

\author{
Kuo-Jung Lee, Mao-Hsiang Hsu, and Huy-Zu Cheng \\ Department of Materials Science and Engineering, I-SHOU University, Kaohsiung 84001, Taiwan \\ Correspondence should be addressed to Kuo-Jung Lee; krlee@isu.edu.tw
}

Received 25 June 2014; Accepted 18 October 2014; Published 12 November 2014

Academic Editor: Yingkui Yang

Copyright (c) 2014 Kuo-Jung Lee et al. This is an open access article distributed under the Creative Commons Attribution License, which permits unrestricted use, distribution, and reproduction in any medium, provided the original work is properly cited.

\begin{abstract}
This research is to investigate the influences of carbon nanotube (CNT) containing friction powder prepared through different process parameters on flexural properties and friction performance of organic brake friction materials. Experimental results indicate significant influence on flexural property and friction performance of organic brake friction materials when the modified $\mathrm{CNT} /$ friction powders are adopted. Particularly for the specimens adopted the modified CNT/friction powders prepared through 2.0 M concentration of catalyst and $30 \% \mathrm{C}_{2} \mathrm{H}_{2}$ show the highest flexural strength, better ductility and toughness, most stable friction coefficient, and lowest weight loss. However, too many amorphous carbon clusters and CNTs aggregation derived from higher concentration of catalyst and ratio of $\mathrm{C}_{2} \mathrm{H}_{2} / \mathrm{N}_{2}$ would cause poor formation of specimens and reduction of reinforcement effectiveness.
\end{abstract}

\section{Introduction}

Many automotive transportation braking systems are adopted organic brake pad against cast iron rotor. The organic brake friction materials consist of various ingredients, such as abrasive, filler, reinforcements, and friction modifier, and are usually bound with phenolic resin binder. Even a difference of one percent or two of ingredient concentrations can also affect brake performance, so composition control is important $[1,2]$. Some literatures [3-10] have focused on the tribological properties of brake lining with different components' compositions. Mutlu et al. [5-8] pointed out that a direct proportionality between hardness and wear resistance due to the complexity of composite structure was not found. They also indicated that heat treatment application changed the microstructure of the brake lining and increased the hardness and supplied a stable friction coefficient. Nonetheless, a complete analysis concerning all the ingredients used in the friction material and their effects on the friction characteristics is seldom found. The high performance brake lining material especially must possess characters of stable friction, reliable strength, and low wear over a wide range of braking conditions. To achieve the low wear property, brake linings need to be tough and heatresistant and have predictable thermal degradation behavior [11]. However, an organic brake friction material subjected to a high temperature environment usually experiences a phenomenon called "fade" $[1,11-16]$, in which the normal lowtemperature coefficient of friction $\mu$ decreases temporarily. An automotive brake friction material requires being light and able to resist high temperature and absorb enough friction energy [14-16] for safety reasons. Because of the inherent thermal degradation character of the organic material, a better thermal resistant material is highly demanded.

Carbon nanotubes with excellent chemical and physical properties have reported improved wear resistance and high strength when mixed in various polymeric materials [17-20]. However, it is difficult to uniformly control the dispersion and distribution of CNTs for preparing the braking friction materials; the application of CNTs to brake friction materials is quite limited [21,22].

In this study, the authors try to prepare modified CNT/ friction powders and CNTs containing organic brake friction materials through sol-gel method with the commercial 
TABLE 1: Process parameters and raw materials used in this study.

\begin{tabular}{|c|c|c|c|c|c|c|c|}
\hline \multirow[b]{2}{*}{ Designation } & \multicolumn{7}{|c|}{ Materials } \\
\hline & $\begin{array}{l}\text { Phenolic resin } \\
\text { (vol\%) }\end{array}$ & $\begin{array}{l}\text { Steel wool } \\
\text { (vol\%) }\end{array}$ & $\begin{array}{c}\text { Cashew } \\
\text { (vol\%) }\end{array}$ & $\begin{array}{l}\mathrm{BaSO}_{4} \\
(\mathrm{vol} \%)\end{array}$ & $\begin{array}{r}\mathrm{CaCO}_{3} \\
\text { (vol\%) }\end{array}$ & Concentration of catalyst & $\mathrm{C}_{2} \mathrm{H}_{2} / \mathrm{N}_{2}$ \\
\hline G & 20 & 20 & 20 & 20 & 20 & $0 \mathrm{M}$ & 0 \\
\hline $\mathrm{C} 0.5$ & 20 & 20 & 20 & 20 & 20 & $0.5 \mathrm{M}$ & $30 / 70$ \\
\hline $\mathrm{C} 1$ & 20 & 20 & 20 & 20 & 20 & $1 \mathrm{M}$ & $30 / 70$ \\
\hline C1.5 & 20 & 20 & 20 & 20 & 20 & $1.5 \mathrm{M}$ & $30 / 70$ \\
\hline $\mathrm{C} 2$ (or A30) & 20 & 20 & 20 & 20 & 20 & $2 \mathrm{M}$ & $30 / 70$ \\
\hline A15 & 20 & 20 & 20 & 20 & 20 & $2 \mathrm{M}$ & $15 / 85$ \\
\hline A30 (or C2) & 20 & 20 & 20 & 20 & 20 & $2 \mathrm{M}$ & $30 / 70$ \\
\hline A45 & 20 & 20 & 20 & 20 & 20 & $2 \mathrm{M}$ & $45 / 55$ \\
\hline A60 & 20 & 20 & 20 & 20 & 20 & $2 \mathrm{M}$ & $60 / 40$ \\
\hline
\end{tabular}

friction powders and grow carbon nanotubes in situ by the CVD process. The process is facilitative to distribute CNTs uniformly for fabricating CNTs containing specimen. The aim of this study was to provide an innovative idea to improve the performance of commercial brake friction materials by adding the modified CNT/friction powders. The effect of CNT reinforcing on flexural properties and friction performance of the CNTs containing specimens are also discussed.

\section{Materials and Methods}

2.1. CNTs Containing Specimen Preparation. Firstly, different modified CNT/friction powders were prepared through different concentration of sol-gel iron catalyst dispersion and CVD process with different $\mathrm{C}_{2} \mathrm{H}_{2} / \mathrm{N}_{2}$ flow ratio. Detailed description of the $\mathrm{CNT} /$ friction powders preparation process has been described by authors' past literature [22]. Table 1 lists different process paremeters and compositions of raw materials prepared for this study. Two modes of process paremeters were designed to fabricate $\mathrm{CNT} /$ friction powders. One is to adopt different concentration of catalyst $(0.0 \mathrm{M}$, $0.5 \mathrm{M}, 1.0 \mathrm{M}, 1.5 \mathrm{M}$, and $2.0 \mathrm{M}$ ) with constant flow ratio of $\mathrm{C}_{2} \mathrm{H}_{2} / \mathrm{N}_{2}(30 / 70 \mathrm{sccm})$. The other mode is to adopt constant concentration of catalyst $(2.0 \mathrm{M})$ with different flow ratio of $\mathrm{C}_{2} \mathrm{H}_{2} / \mathrm{N}_{2}(15 / 85,30 / 70,45 / 55$, and $60 / 40 \mathrm{sccm})$. All raw material powders were mixed and press-molded at $180^{\circ} \mathrm{C}$ under a unidirectional pressure of $100 \mathrm{MPa}$ to make round disks of $25.4 \mathrm{~mm}$ in diameter and $10 \mathrm{~mm}$ in thickness.

2.2. Open Porosity. The open porosity of fabricated specimens which were experienced by different process parameters was measured by the water immersion method according to the ASTM C-20.

2.3. Flexural Strength. The flexural strength was determined using three-point bending test on the Instron test machine (Shimadzu, AGS-500A, Japan) with the crosshead speed $1 \mathrm{~mm} / \mathrm{min}$ based on the ASTM D-790 method. The cross section of the specimen bar is $5 \times 2.5 \mathrm{~mm}$ and the length of the support span is $35 \mathrm{~mm}$. The flexural strength of specimens is calculated according to the equation listed in the following:

$$
\sigma=\frac{3 P L}{2 W T^{2}},
$$

where $P$ is the maximum load, $L$ is the length of support span, and $W$ and $T$ are the width and the thickness of the specimens, respectively. At least five specimens were tested for each composite and the flexural strength values were averaged from five tests. Typical stress-strain curves of different specimens with different process parameters are also selected to compare.

2.4. Friction and Wear Tests. Wear testing was conducted in a normal air environment using a homemade disc-ondisc sliding wear tester (Figure 1). The counterface material is SAE-G2500 gray cast iron (the rotor material). Prior to testing, the wear test specimens (included cast iron disc and CNT containing materials) were polished through a level of \#1200 grit paper, followed by ultrasonic cleaning and drying. A fixed load of $1.2 \mathrm{MPa}$, constant rotor speed of $1000 \mathrm{rpm}$ (linear speed is $0.67 \mathrm{~m} / \mathrm{s}$ ), and testing time of $300 \mathrm{sec}$ (sliding distance is $200 \mathrm{~m}$ ) were used in test. A strain gage-equipped LRK-100K load cell (NTS Technology, Nara, Japan) was used to determine the friction coefficient. At least five specimens were tested for each composite and the weight loss was measured and averaged from five tests.

2.5. Microstructure. A Hitachi S-4700 (Hitachi, Japan) scanning electron microscope (SEM) was used to examine morphologies of those CNT/friction powders and typical worn surface of those specimens after experiencing the wear test.

\section{Results and Discussion}

3.1. Microstructure. The microstructures of modified CNT/ friction powders are shown in Figure 2. As indicated by arrow signs in Figure 2(b), many CNTs and amorphous carbon clusters were generated at the same time through the CVD process. It is also noted that many CNTs dispersed and entwined with a commercial friction powder particle. This 

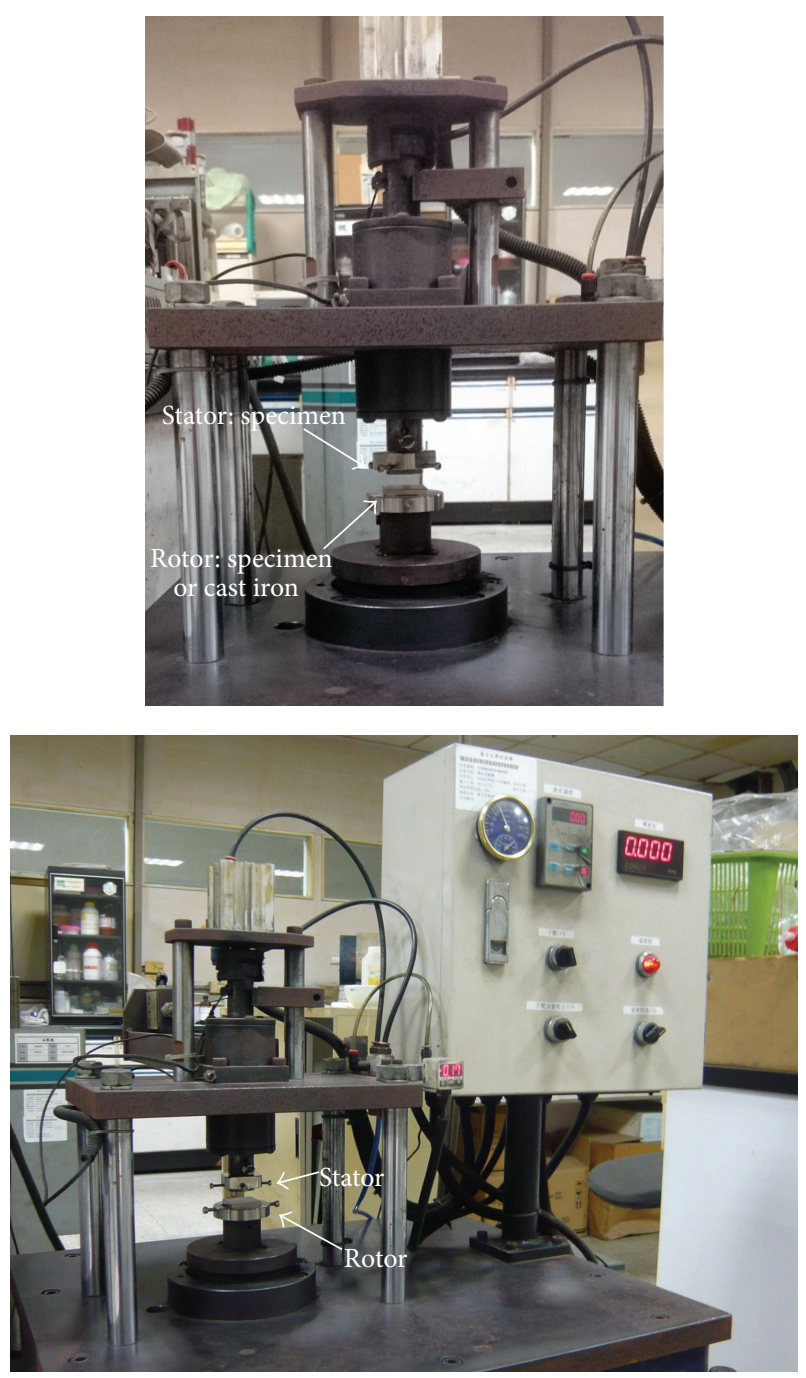

FIGURE 1: Device for friction and wear tests.

result would facilitate CNTs to distribute uniformly in fabricated specimens when these modified CNT/friction powders were mixed uniformly. According to our observation of modified CNT/friction powders, larger quantities of CNTs and extra carbon product (graphite particles or amorphous carbon clusters, etc.) were derived through higher flow ratio of $\mathrm{C}_{2} \mathrm{H}_{2} / \mathrm{N}_{2}$. However, we still do not have sufficient data to identify the distinct quantitative amounts of CNTs and amorphous carbon cluster definitely.

3.2. Open Porosity. Figure 3 shows the dependence of open porosity with different process parameters. Among all specimens, the green specimen $G$ (with commercial friction material's components) possesses the highest open porosity (12 vol \%). The CNTs containing specimens showed lower porosity than that of green specimen. The $\mathrm{A} 30$ specimen with $2.0 \mathrm{M}$ concentration of catalyst and flow ratio of $\mathrm{C}_{2} \mathrm{H}_{2} / \mathrm{N}_{2}$ $=30 / 70$ shows the lowest open porosity $(7.4 \mathrm{vol} \%)$. One possible explanation for the phenomena is that CNTs of modified CNT/friction powders could easily fill those small pores between friction powders during the formation of specimens. It should be noted that the open porosity of CNTs containing specimens decreases roughly with the concentration of catalyst. However, the specimens (A45 and A60) with higher ratio of $\mathrm{C}_{2} \mathrm{H}_{2} / \mathrm{N}_{2}$ did not show lower open porosity. The phenomena can be attributed to that the modified $\mathrm{CNT} /$ friction powders in this study were not purified. Although higher ratio of $\mathrm{C}_{2} \mathrm{H}_{2} / \mathrm{N}_{2}$ could derive larger quantities of CNTs, much extra carbon products (graphite particles or amorphous carbon clusters, etc.) were also derived. Dueto the poor bonding between the matrix and extra carbon products, these carbon products will cleave or break away from the matrix and then cause a poor formation of specimens. Another reason might be with CNT content increasing, the CNT aggregations become more serious in composites. These aggregate CNTs were difficult to be pressmolded and also caused a poor formation of specimens. These two reasons would cause these modified CNT/friction powders to be press-molded into a specimen difficultly and incompletely.

3.3. Flexural Property. The stress-strain curves for fabricated specimens are shown in Figure 4. As seen from these curves, it is noticeable that the specimens C1.5, C2/A30, and A45 have higher fracture strengths and larger strains to failure than the green specimen G. For CNTs containing specimens ( 0.5 , $\mathrm{C} 1, \mathrm{C} 1.5, \mathrm{C} 2 / \mathrm{A} 30$, and A45), after the maximum stress, the curves drop gradually and have a larger ductility, exhibiting a pseudoductile fracture mode, whereas the green specimen G shows a brittle fracture behavior due to sharp decline of stress and lower fracture strain indicating introduction of CNTs is contributed to the improvement of flexural ductility and toughness. It is thought that the partial CNTs could bear the load; thus, they absorb the energy during the bending test.

As shown in Figure 5, the A30 (or C2) specimen shows the highest flexural strength. The flexural strength of CNTs containing specimens with different process parameters is higher than that of the green specimen except for C0.5, $\mathrm{Cl}$, and A15 specimens. These experimental results probably illustrate that appropriate amount of CNTs do improve the flexural strength of the specimens. It is also noted that the flexural strength increases with the concentration of catalyst but decreases when the flow ratio of $\mathrm{C}_{2} \mathrm{H}_{2} / \mathrm{N}_{2}$ is more than 30/70. As shown in Figure 6, the flexural strength of specimens is roughly inversely proportional to their open porosity. This observation implies that CNTs could improve the flexural strength of CNTs containing specimens; however, too many amorphous carbon clusters or the aggregation of the CNTs derived from high ratio of $\mathrm{C}_{2} \mathrm{H}_{2} / \mathrm{N}_{2}$ would cause the poor formation of the specimen and deteriorate the reinforcement effectiveness.

3.4. Friction and Wear. Typical friction coefficient curves in response to concentration of catalyst and ratio of $\mathrm{C}_{2} \mathrm{H}_{2} / \mathrm{N}_{2}$ under the constant load (1.2 MPa) and speed (1000 rpm) are shown in Figure 7. For most specimens, the friction coefficient rose abruptly when wear test started and then declined slowly toward a steady value. In comparison with 


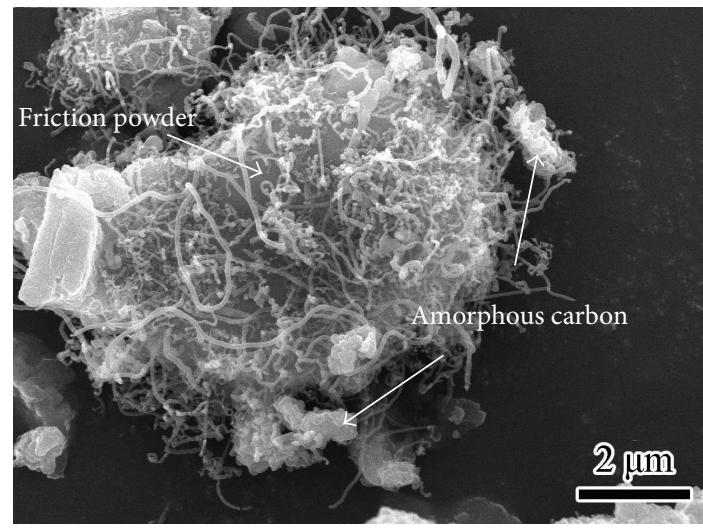

(a)

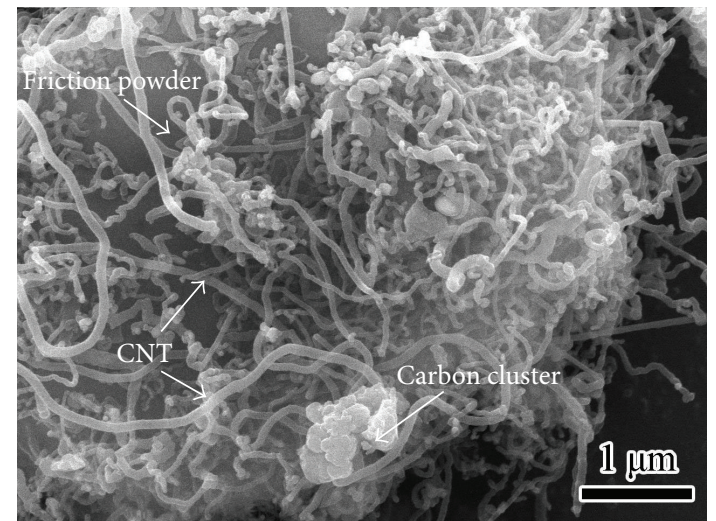

(b)

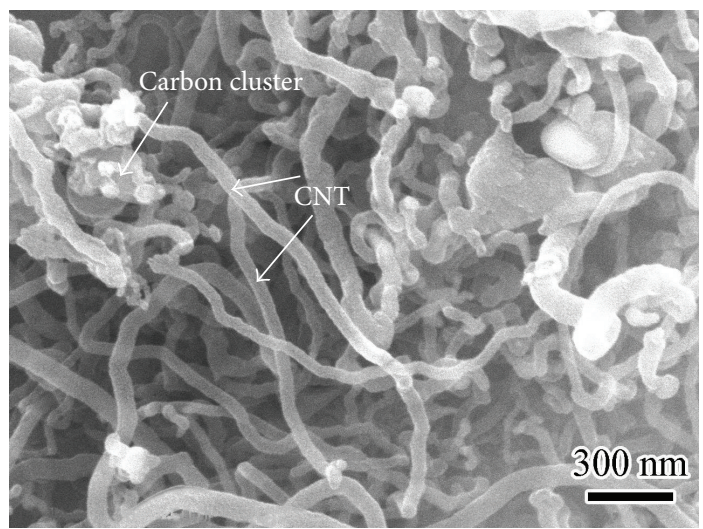

(c)

Figure 2: Microstructures of CNT/friction powders prepared through flow ratio of $\mathrm{C}_{2} \mathrm{H}_{2} / \mathrm{N}_{2}=45 / 55$.

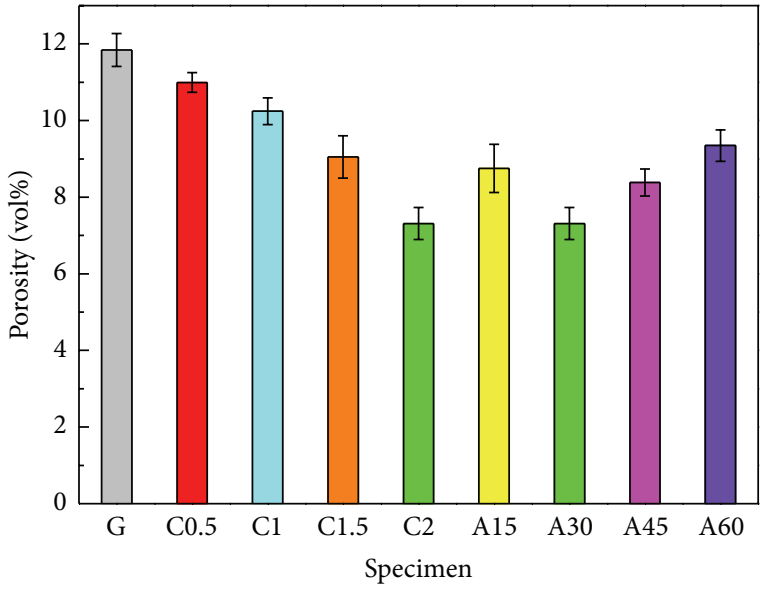

FIGURE 3: Open porosity of CNTs containing specimens with different process paremeters.

the green specimen, the friction coefficient curves of the CNTs containing specimens were almost lower and more stable. As the concentration of catalyst increased, the friction coefficient curves of CNTs containing specimens during

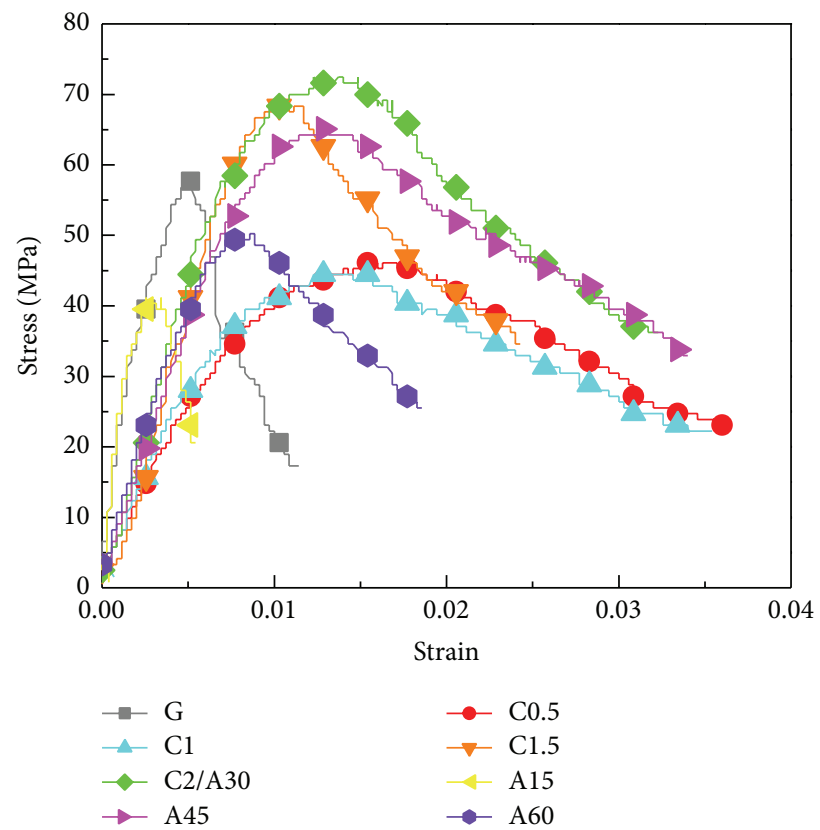

FIGURE 4: Stress-strain curves of CNTs containing specimens with different process paremeters. 


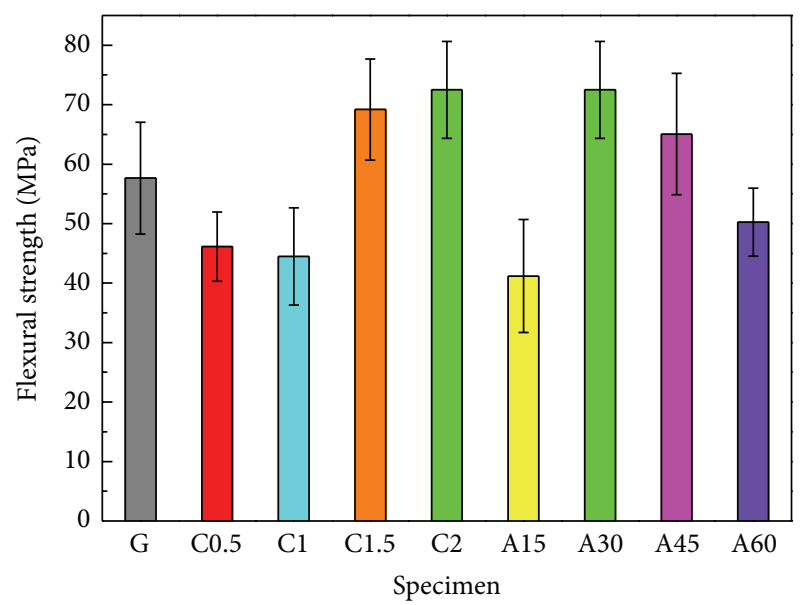

FIGURE 5: Flexural strength of CNTs containing specimens with different process paremeters.

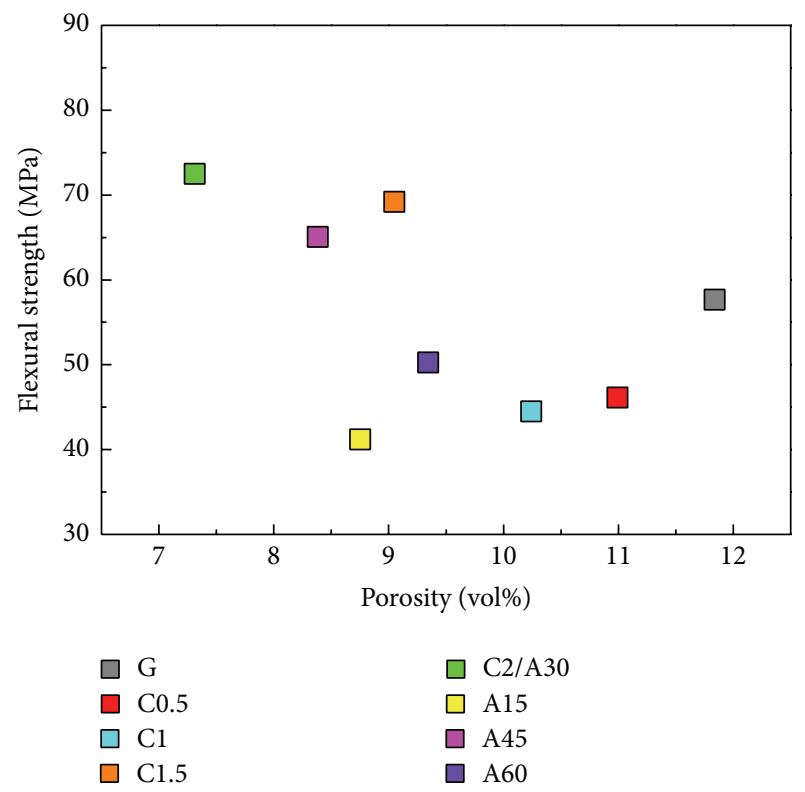

FIGURE 6: Flexural strength versus porosity of CNTs containing specimens with different process paremeters.

the wear test were lower and smoother. Among those specimens with different concentration of catalyst, the C2 specimen shows the lowest friction coefficient and more stable variation in friction coefficient curve. Among those specimens with different ratio of $\mathrm{C}_{2} \mathrm{H}_{2} / \mathrm{N}_{2}$, the $\mathrm{A} 30$ specimen shows the lowest and most stable friction coefficient curve. Nevertheless, specimens with higher ratio of $\mathrm{C}_{2} \mathrm{H}_{2} / \mathrm{N}_{2}$ did not reflect lower and more stable friction coefficient curve. This phenomenon will be discussed further in the next paragraph.

Weight losses of specimens with different process parameters after experiencing the constant load (1.2 MPa) and speed $(1000 \mathrm{rpm})$ wear test were compared in Figure 8. Among all CNTs containing specimens, the A30 (or C2) specimen had the lowest weight losses $(19 \mathrm{mg})$. The weight losses decrease further with the concentration of catalyst. However,

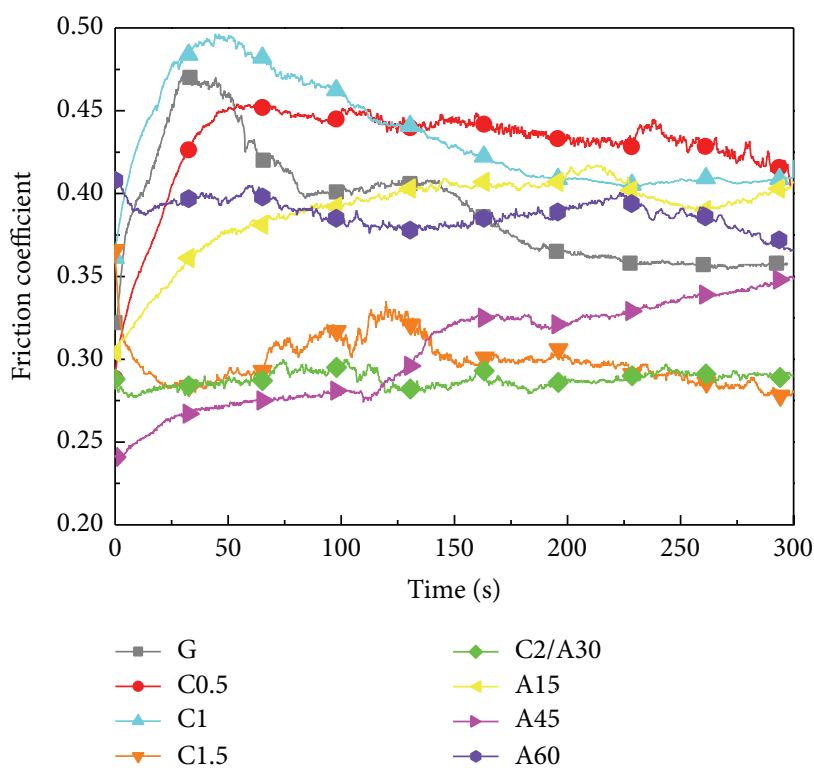

FIgURE 7: Typical friction coefficient curves of CNTs containing specimens with different process paremeters during wear tests.

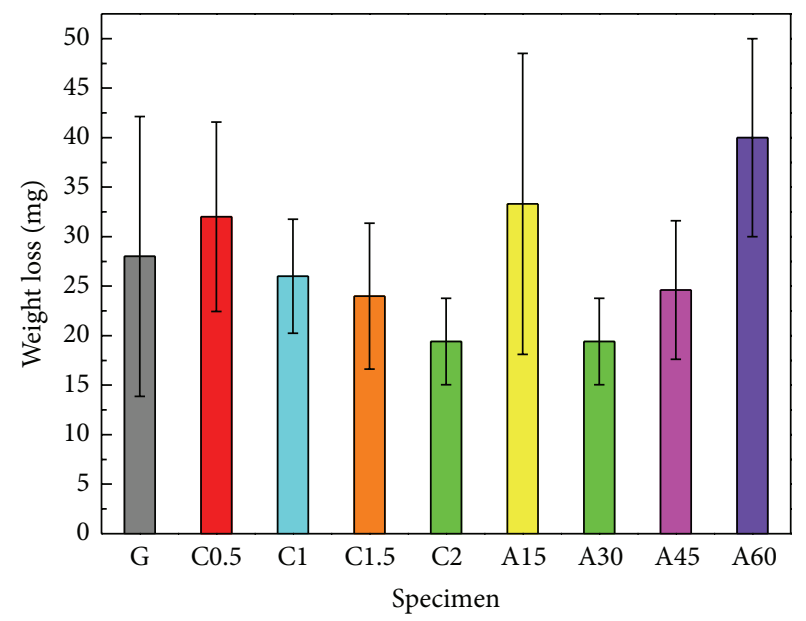

Figure 8: Weight losses of CNTs containing specimens with different process paremeters after wear tests.

the weight losses increase with the ratio of $\mathrm{C}_{2} \mathrm{H}_{2} / \mathrm{N}_{2}$ when the flow ratio of $\mathrm{C}_{2} \mathrm{H}_{2} / \mathrm{N}_{2}$ is more than $30 / 70$. The $\mathrm{A} 60$ specimen had the largest weight losses $(40 \mathrm{mg})$. It seems that the weight loss of the green specimen is more fluctuant and much higher than all of the CNTs containing specimens. Based on the observation of friction and wear results, it implies that although CNTs could improve tribological performance of organic brake friction materials, larger quantities of amorphous carbon clusters and CNT aggregations in $\mathrm{CNT} /$ friction powder produced from high ratio of $\mathrm{C}_{2} \mathrm{H}_{2} / \mathrm{N}_{2}$ would cause poor formation of CNTs containing specimens and reduce efficiency of tribological improvement. It should be noted that the weight losses of specimens decrease with their flexural strength and roughly proportional to their open porosity. It also shows that the weight losses of specimens are 


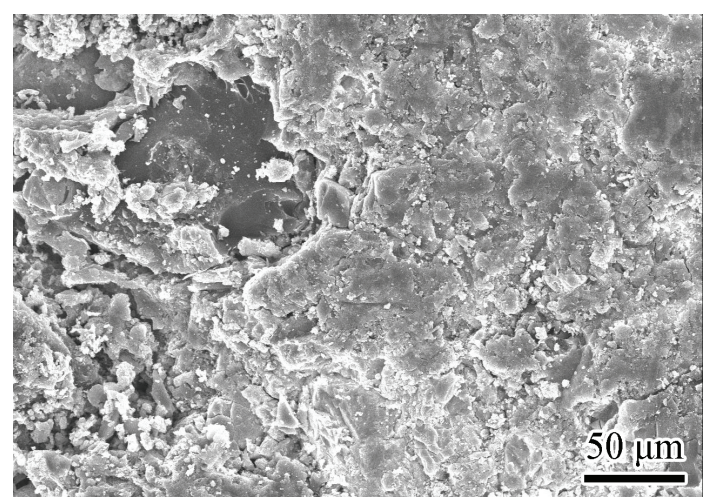

(a)

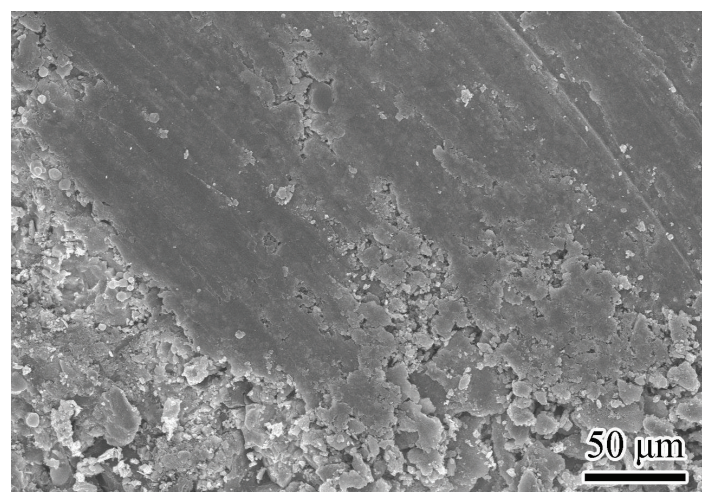

(c)

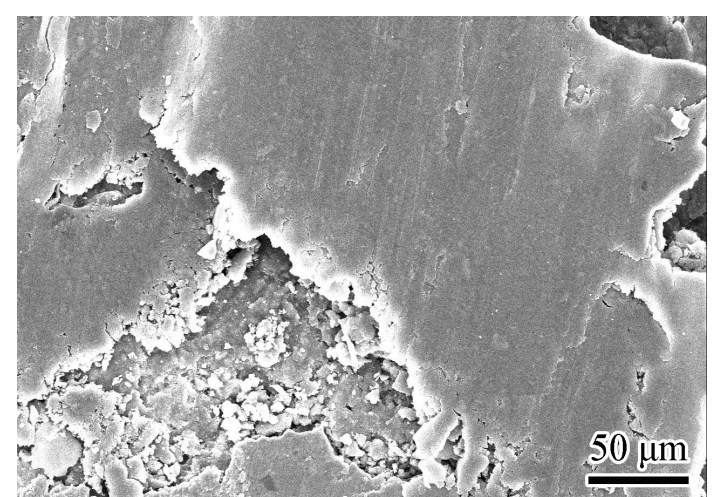

(b)

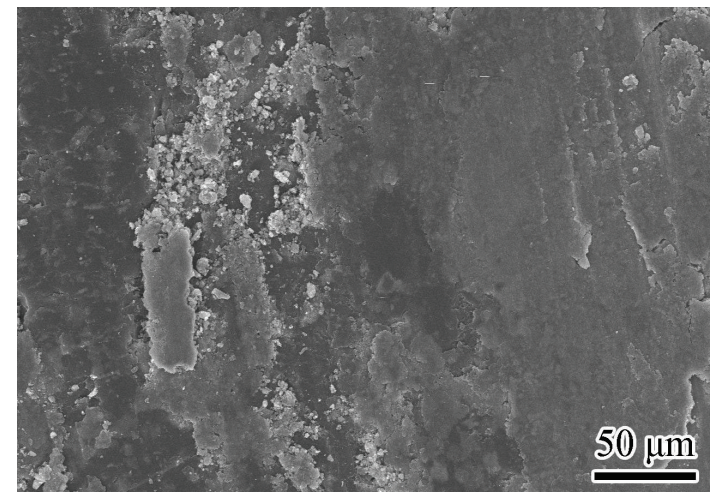

(d)

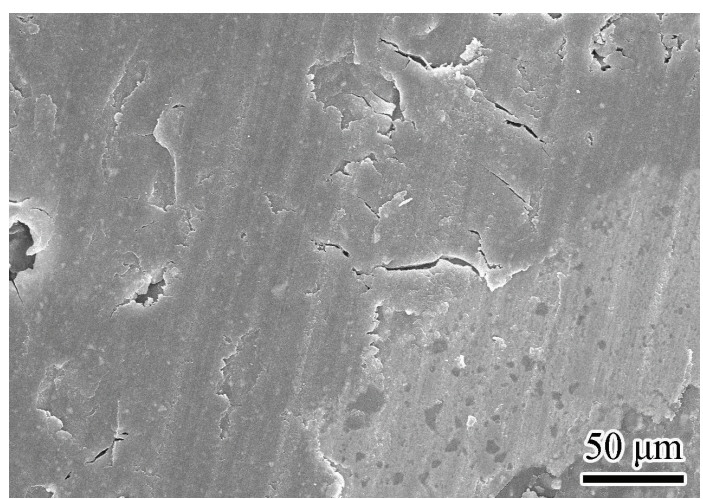

(e)

FIGURE 9: Worn surface morphologies of CNTs containing specimens with different concentration of catalyst after wear tests. (a) G (green specimen), (b) C0.5, (c) C1, (d) C1.5, and (e) C2.

roughly related to their friction coefficient curves. The lower the friction coefficient is and the smoother the curve is, the lower the weight loss is.

3.5. Worn Surface Morphology. Figures 9 and 10 show the typical worn surface morphology of CNTs containing specimens with different process parameters after experiencing the wear test. As shown in Figure 9(a), the worn surface of the green specimen exhibited a severe damaged, rough, and random morphology. Pores and cracks were generated during the wear test and existed throughout the specimen. This worn surface as shown in Figure 9(a) was responsible for the high and unstable friction coefficient curve as indicated in Figure 7 and the large weight loss during the wear process (Figure 8). On the worn surface of the specimen with $0.5 \mathrm{M}$ concentration of catalyst, a smoother surface was observed, though a few cracks and small pores were still observed (Figure 9(b)). As the concentration of catalyst increased, the worn surface exhibited remarkably different morphology from that was observed on the green specimen. As shown in Figures 9(d)-9(e), a smooth and quite adherent film was formed on the worn surface.

As shown in Figure 10, among the worn surface of the specimens with different ratio of $\mathrm{C}_{2} \mathrm{H}_{2} / \mathrm{N}_{2}$, the worn surface 


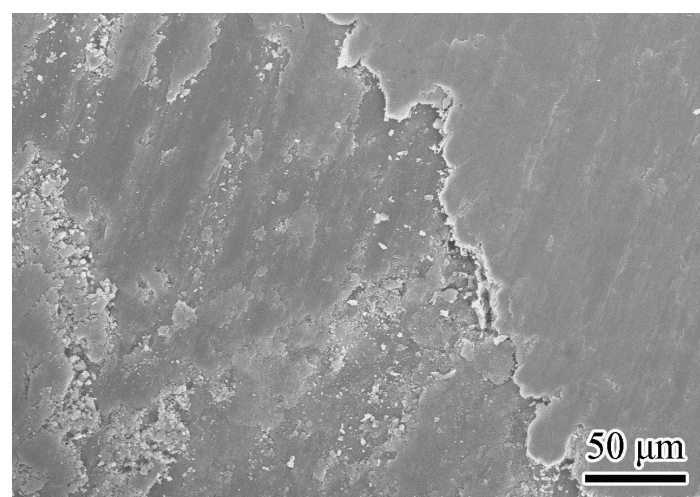

(a)

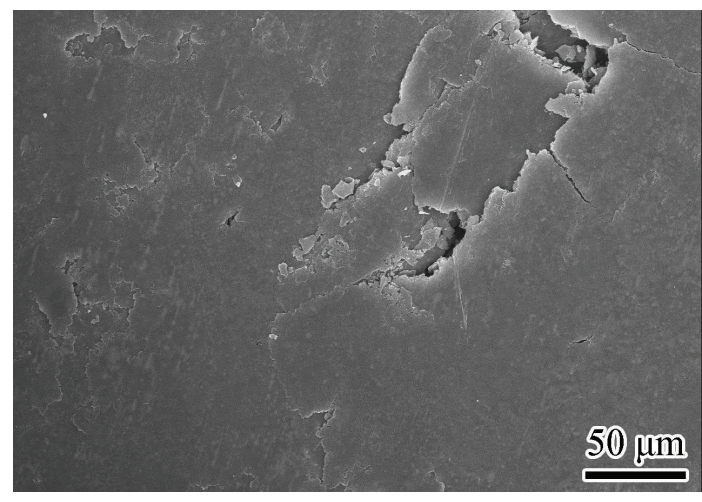

(c)

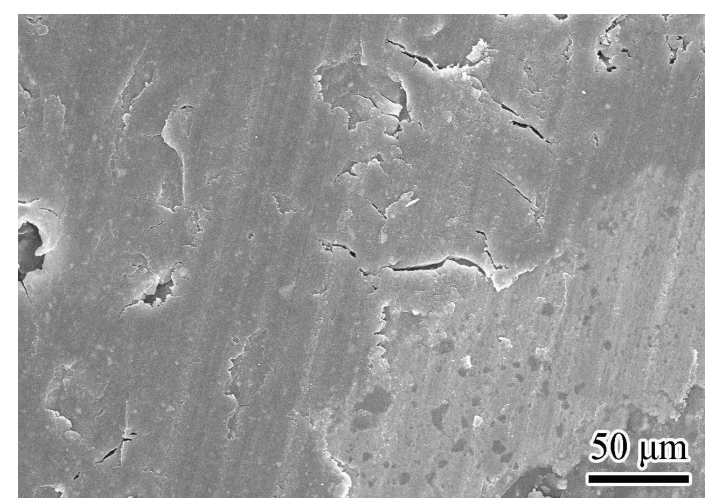

(b)

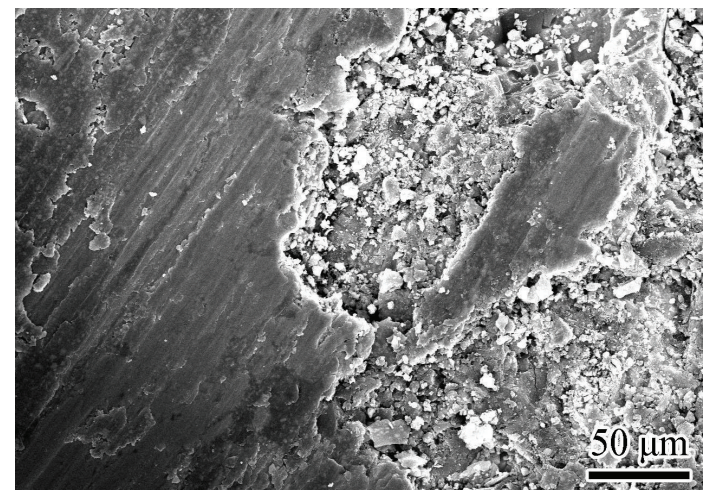

(d)

Figure 10: Worn surface morphologies of CNTs containing specimens with different ratio of $\mathrm{C}_{2} \mathrm{H}_{2} / \mathrm{N}_{2}$ after wear tests. (a) A15, (b) A30/C2, (c) A45, and (d) A60.

of A30 specimen showed the most stable morphology; a smooth and dense lubricating film was formed on the worn surface. This phenomenon is responsible for the lowest, most stable friction coefficient curve and the lowest weight loss of A30 specimen during the wear process as indicated in Figures 5 and 6 . However, when the flow ratio of $\mathrm{C}_{2} \mathrm{H}_{2} / \mathrm{N}_{2}$ is more than 30/70, the worn surface of the A45 and A60 specimens becomes unstable. The lubricating film was damaged; pores and cracks were generated on worn surface of A60 specimen. The worn surface was responsible for the high and unstable friction coefficient curve as indicated in Figure 7 and the large weight loss during the wear process (Figure 8).

Based upon our experimental results, we conclude that CNTs could improve the mechanical and tribological performances of CNTs containing specimens. The specimen with modified $\mathrm{CNT} /$ friction powder shows more excellent mechanical and tribological performance than that of the specimen only with traditional commercial friction powder. However, if the flow ratio of $\mathrm{C}_{2} \mathrm{H}_{2} / \mathrm{N}_{2}$ is higher than the amount for CNTs synthesis required at the specific catalyst concentration, many amorphous carbon clusters would be produced. The formation of these carbon clusters thus caused the poor formation of the specimen and reduced reinforcement effectiveness. There is another possibility that larger quantities of flustered and aggregate CNTs produced from high $\mathrm{C}_{2} \mathrm{H}_{2} / \mathrm{N}_{2}$ ratio would also cause the poor formation of the specimen. It seems that the well balance in proper concentration of catalyst and ratio of $\mathrm{C}_{2} \mathrm{H}_{2} / \mathrm{N}_{2}$ could provide the best mechanical and tribological performance of CNT containing specimens.

\section{Conclusions}

The specimen with modified CNT/friction powder shows more excellent mechanical and tribological performance than that of the specimen only with traditional commercial friction powder. CNTs could improve the flexural properties and tribological performances of organic brake friction materials. The CNTs containing specimens exhibit larger strength, ductility, and pseudoplastic fracture modes. The CNTs containing specimens also exhibit lower weight loss and more stable friction coefficient during the wear test. However, too many amorphous carbon clusters and aggregate CNTs derived from high ratio of $\mathrm{C}_{2} \mathrm{H}_{2} / \mathrm{N}_{2}$ or too little CNTs produced from low catalyst concentration would cause poor formation and reduce reinforcement effectiveness. It seems that the well balance in proper concentration of catalyst and ratio of $\mathrm{C}_{2} \mathrm{H}_{2} / \mathrm{N}_{2}$ could provide the best flexural properties and tribological performances of CNTs containing specimens. In this study, the CNTs containing specimens prepared through $2.0 \mathrm{M}$ catalyst concentration and $30 \% \mathrm{C}_{2} \mathrm{H}_{2}$ show the lowest open porosity and best properties. 


\section{Conflict of Interests}

The authors declare that there is no conflict of interests regarding the publication of this paper.

\section{Acknowledgments}

The authors are grateful to the Ministry of Science and Technology, National Science Council, and I-SHOU University of Taiwan, for their support of the research presented under the Contract nos. MOST 103-2221-E-214-007, NSC 102-2221E-214-015, NSC 101-2221-E-214-021, and NSC 99-2221-E-214036.

\section{References}

[1] D. Chan and G. W. Stachowiak, "Review of automotive brake friction materials," Proceedings of the Institution of Mechanical Engineers, Part D: Journal of Automobile Engineering, vol. 218, no. 9, pp. 953-966, 2004.

[2] P. Gopal, L. R. Dharani, and F. D. Blum, "Load, speed and temperature sensitivities of a carbon-fiber-reinforced phenolic friction material," Wear, vol. 181-183, no. 2, pp. 913-921, 1995.

[3] H. Jang, J. S. Lee, and J. W. Fash, "Compositional effects of the brake friction material on creep groan phenomena," Wear, vol. 250-251, no. 2, pp. 1477-1483, 2001.

[4] Y. C. Kim, M. H. Cho, S. J. Kim, and H. Jang, "The effect of phenolic resin, potassium titanate, and CNSL on the tribological properties of brake friction materials," Wear, vol. 264, no. 3-4, pp. 204-210, 2008.

[5] I. Mutlu, O. Eldogan, and F. Findik, "Tribological properties of some phenolic composites suggested for automotive brakes," Tribology International, vol. 39, no. 4, pp. 317-325, 2006.

[6] I. Mutlu, O. Eldogan, and F. Findik, "Production of ceramic additive automotive brake lining and investigation of its braking characterisation," Industrial Lubrication and Tribology, vol. 57, no. 2, pp. 84-92, 2005.

[7] I. Mutlu, C. Oner, and F. Findik, "Boric acid effect in phenolic composites on tribological properties in brake linings," Materials \& Design, vol. 28, no. 2, pp. 480-487, 2007.

[8] I. Mutlu, C. Oner, I. Cevik, and F. Findik, "Wear performance of some phenolic composites with boric acid," Industrial Lubrication and Tribology, vol. 59, no. 1, pp. 38-45, 2007.

[9] X. Xin, C. G. Xu, and L. F. Qing, "Friction properties of sisal fibre reinforced resin brake composites," Wear, vol. 262, no. 5-6, pp. 736-741, 2007.

[10] P. J. Blau and H. M. Meyer III, "Characteristics of wear particles produced during friction tests of conventional and unconventional disc brake materials," Wear, vol. 255, no. 7-12, pp. 1261-1269, 2003.

[11] A. E. Anderson, "Consultant: friction and wear of automotive brakes," in ASM Handbook, vol. 18, pp. 569-577, ASM International, Novelty, Ohio, USA, 1992.

[12] P. H. S. Tsang, M. G. Jacko, and S. K. Rhee, "Comparison of chase and inertial brake dynamometer testing of automotive friction material," in Proceedings of the International Conference on Wear of Materials, K. C. Ludema, Ed., pp. 129-137, American Society of Mechanical Engineers, New York, NY, USA, 1985.

[13] M. G. Jacko, "Physical and chemical changes of organic disc pads in service," Wear, vol. 46, no. 1, pp. 163-175, 1978.
[14] P. Gopal, L. R. Dharani, and F. D. Blum, "Fade and wear characteristics of a glass-fiber-reinforced phenolic friction material," Wear, vol. 174, no. 1-2, pp. 119-127, 1994.

[15] P. Gopal, L. R. Dharani, and F. D. Blum, "Hybrid phenolic friction composites containing Kevlar pulp part I. Enhancement of friction and wear performance," Wear, vol. 193, no. 2, pp. 199206, 1996.

[16] P. Gopal, L. R. Dharani, and F. D. Blum, "Hybrid phenolic friction composites containing Kevlar pulp: part II-wear surface characteristics," Wear, vol. 193, no. 2, pp. 180-185, 1996.

[17] O. Jacobs, W. Xu, B. Schädel, and W. Wu, "Wear behaviour of carbon nanotube reinforced epoxy resin composites," Tribology Letters, vol. 23, no. 1, pp. 65-75, 2006.

[18] A. B. Sulong, J. Park, N. Lee, and J. Goak, "Wear behavior of functionalized multiwalled carbon nanotube reinforced epoxy matrix composites," Journal of Composite Materials, vol. 40, no. 21, pp. 1947-1960, 2006.

[19] L. C. Zhang, I. Zarudi, and K. Q. Xiao, "Novel behaviour of friction and wear of epoxy composites reinforced by carbon nanotubes," Wear, vol. 261, no. 7-8, pp. 806-811, 2006.

[20] Z. Yang, B. Dong, Y. Huang, L. Liu, F.-Y. Yan, and H.-L. Li, "Enhanced wear resistance and micro-hardness of polystyrene nanocomposites by carbon nanotubes," Materials Chemistry and Physics, vol. 94, no. 1, pp. 109-113, 2005.

[21] H. J. Hwang, S. L. Jung, K. H. Cho, Y. J. Kim, and H. Jang, "Tribological performance of brake friction materials containing carbon nanotubes," Wear, vol. 268, no. 2-3, pp. 519$525,2010$.

[22] K.-J. Lee, M.-H. Hsu, H.-Z. Cheng et al., "Tribological and mechanical behavior of carbon nanotube containing brake lining materials prepared through sol-gel catalyst dispersion and CVD process," Journal of Alloys and Compounds, vol. 483, no. 1-2, pp. 389-393, 2009. 

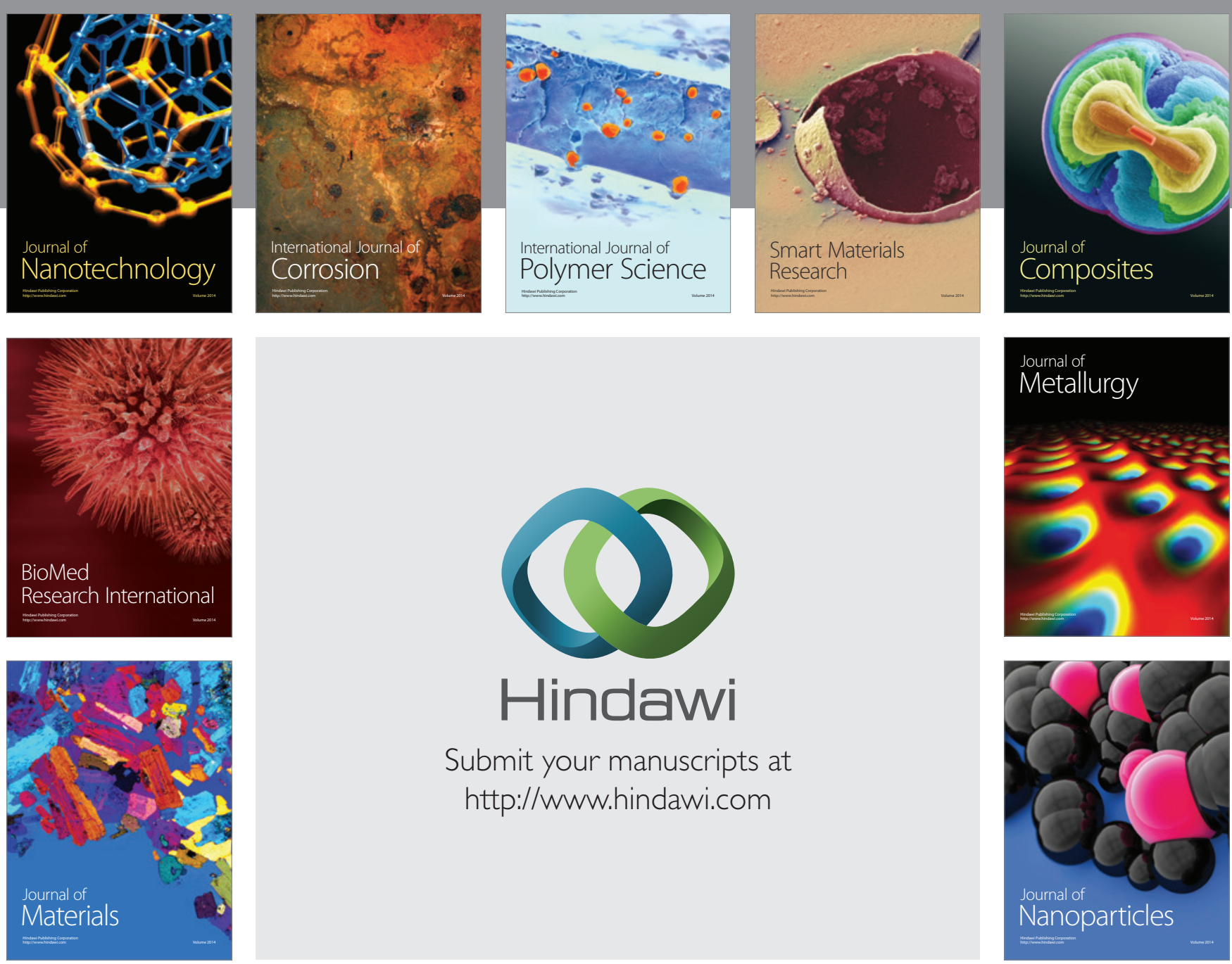

Submit your manuscripts at http://www.hindawi.com
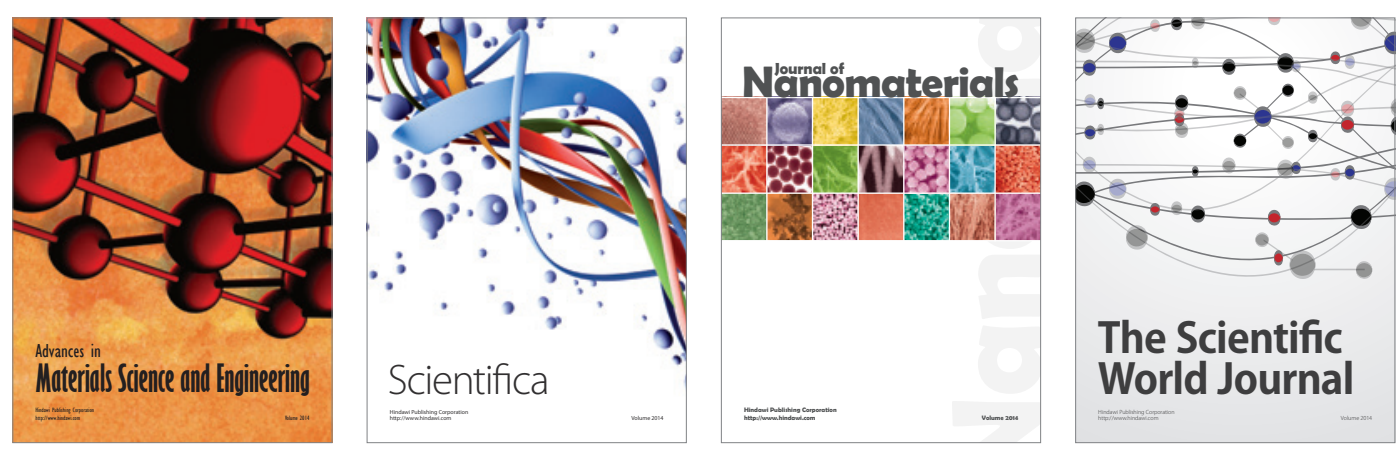

\section{The Scientific World Journal}
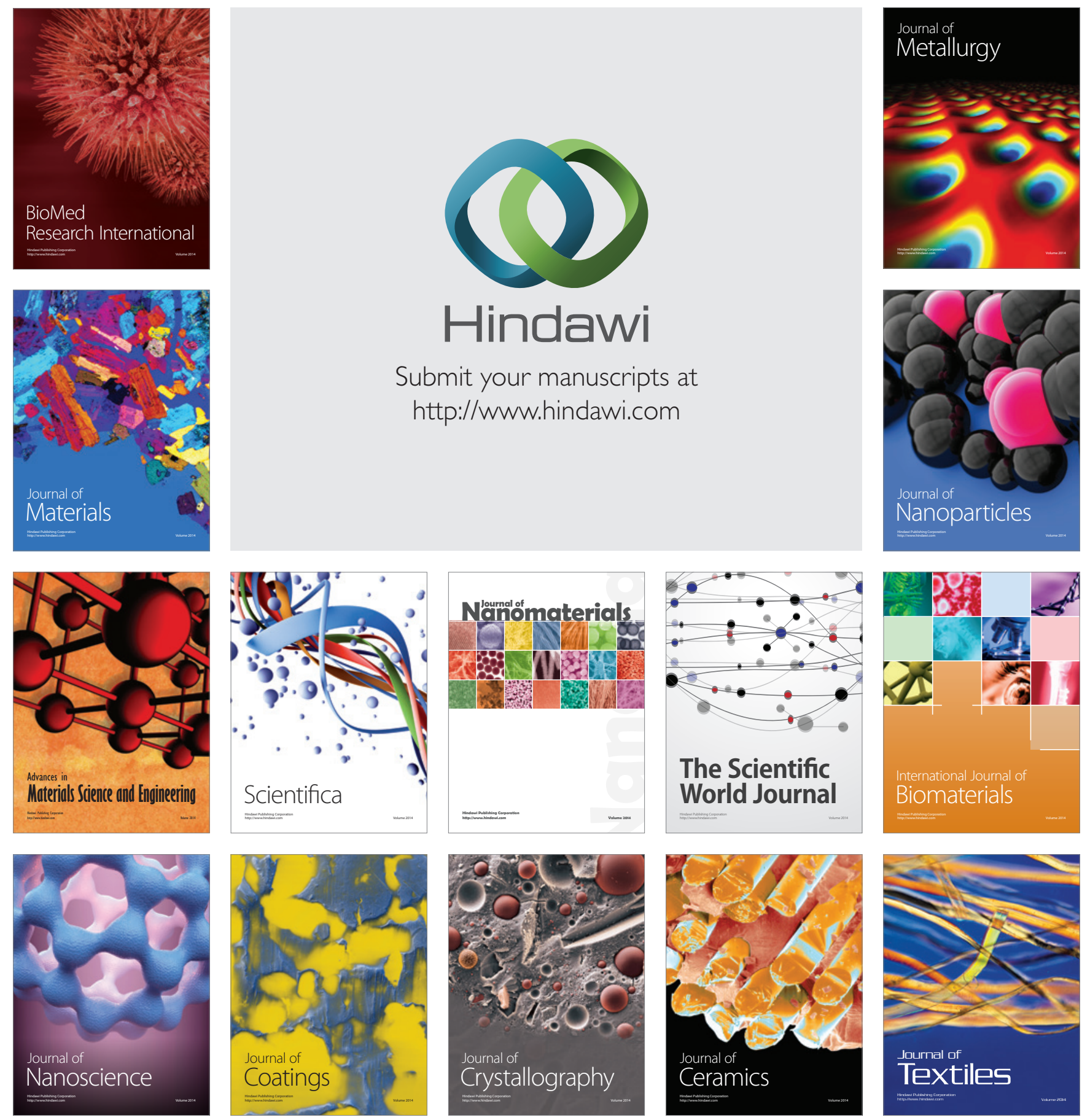